Jap.Psychol Research.

No. 21955

\title{
AN EXPERIMENTAL STUDY OF EXTINCTIN IN THE STRAIGHT RUNWAY*
}

\author{
SHINKRO IWAHARA \\ Nara Women's University
}

Effects of changes of stimulus conditions during extinction of instrumental conditioning have been studies by Hunter (4), Skinner (7), Reynolds (5), (6), Horn and Heron (3) and Gagné (2). They presented external stimuli before conditioned responses were elicited and all except Skinner found the facilitation of response strength in extinction. They called the phenomenon disinhibition.

The purpose of this study was to investigate what would happen when the stimulus conditions were changed at the goal box, that is, after rather than before the conditioned response was elicited in a simple runway learning.

$$
\begin{aligned}
& \text { EXPERIMENT I } \\
& \begin{array}{|ll|ll|l|l|l|}
\multicolumn{3}{ll}{D_{3} C_{2}} & D_{2} C_{1} & D_{1} \\
\hline G B & 2 & G B & 1 & B & S B \\
\hline
\end{array} \\
& \mathrm{C}=\text { curtain } \mathrm{D}=\text { door } \mathrm{GB} 1 \text { = goal box } \\
& \text { GB } 2 \text { =empty box } \mathrm{SB}=\text { starting box }
\end{aligned}
$$

Procicdure

Subjects. -Eighteen experimentally naive albino rats approximately eight months of age were used.

Apparatus.-The equipment consisted of a simple runway four feet long, four inches wide and five inches and a half deep. At one end of this runway was a starting box (SB), one foot long, four inches wide and five inches and half deep. At the other end there were two similar boxes (GB 1 and GB 2). Each of these was same size as SB. The floor plan of the apparatus is show in Figure 1.

Three guillotine doors (D1, D2 and D3) and two curtains, black (C1) and white $\left(\mathrm{C}_{2}\right)$ were located as indicated
* This experiment was conducted in 1953 at the University of Missouri, U.S.A., under the supervision of Dr. Nissim Levy, now at Brown University. A brief summary of this paper was report at the Chicago meeting of the Midwestern Psychological Association, May 1953. The writer wishes his appreciation to $\mathrm{Dr}$. Levy and $\mathrm{Mr}$. Reed Lawson of the University of Missouri for their many helpful suggestions. in the same figure. The entire apparatus was covered by wire mesh and was painted black. Two 150 watt lamps illuminated the apparatus from three feet and a half above the middle of the apparatus.

Accomodation.-Animals were placed on a maintainance schedule six days 
before the training period. They were fed in individual cages for one hour at approximately the same time as they were to be fed during the training and extinction periods. From the third through the sixth day of the maintainance period the rats were handled by the experimenter for two minutes a day. On the sixth day, they were individually placed in SB and were allowed to explore the alley and GB 1 for two minutes. During the exploration D1 and D2 were opened and C1 was not hung. GB2 was not exposed to the animals during exploration and training.

Training.-The training period consisted of 10 training trials per day for six days. The day after exploration, the rats were given first 10 daily training trials. They were placed in $\mathrm{SB}$ and five seconds later, D1 was opened and a stop-watch started. The watch was stopped when the animal's body exclusive of the tail had left the runway and passed $\mathrm{C} 1$ and $\mathrm{D} 2$ to GB 1. This time interval was recorded as the running time throughout the experiment. The rats were then allowed to eat food in GB 1 for 20 seconds and returned to the individual detention cage for about six minutes. After the completion of the daily training trials, the animals were fed for a period one one hour.

The experimental food was moist and ground Purina Chow in a glass bin placed in $G B$ 1, while the food given in the living cages was dry and ground
Purina Chow.

Extinction.-Approximately six minutes after the last training trial on the sixth training day, the rats were given 15 extinction trials with an intertrial interval of six to ten minutes. They found no food bin in GB 1 as in the customary extinction procedure and they were kept in the empty box for 20 seconds. If the rat did not get to GB 1 in two minutes, a trial was counted and it was returned to the detention cage for the next run.

On the next day same conditions were used for seven additional trials but on the eighth trial, D3 was opened and the rats were permitted to enter GB 2 which they had never experienced. On this critical trial the rats were given enough time to touch the white cartain or $\mathrm{C}_{2}$ so that they could get into GB 2 by themselves. All of the rats found $\mathrm{D} 3$ opened and reached GB 2 within 20 seconds after they passed D2. Five more trials were run under these conditions. These five extinction trials were called post-extinction trials.

\section{RESULTS}

Running times were transformed into logarithmic scores. These transformed values were assumed to be a linear function of the habit strength. The reliability of the ranning times during the whole extinction period was measured by the split-half method. A high value of .839 was obtained.

Figure 2 indicated the transformed running times on the second extinc- 
tion day. The mean value on the eighth critical trial was 1.410 and the mean for the first post-extinction run was be difficult to regard the new stimulus as directly affecting the response on the following trial, since the time inter-

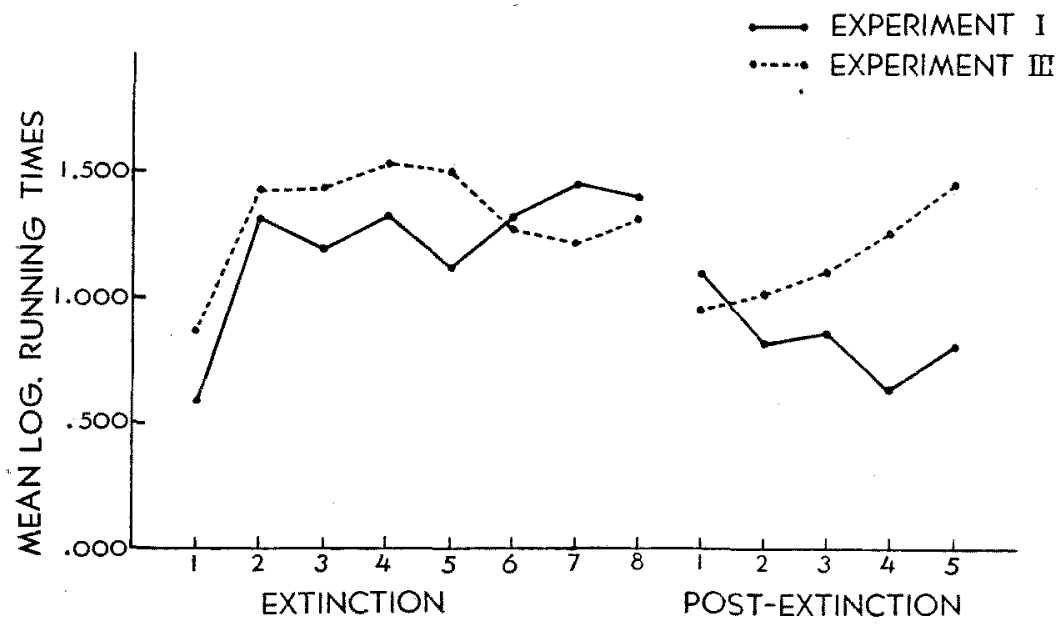

Fig. 2. Efffets of Stmules Changes on Ruxica Tumes

1.110. The difference between the two means was significant at the .05 confidence level by the matched $t$ test. A $t$ of 2.24 was observed with $17 d f$. The mean running time seemed to decrease on later trials but only one significant difference was obtained between the first and the fourth post-extinction trials, using the same $t$ test.

\section{DISCUSSION}

The results clealy indicated that the introduction of a new stimulus object during extiction had facilitating effect on the following responses. The theory of disinhibition might explain that the new stimulus complex GB 2 would disinhibit the conditioned inhibition to GB 1 as well as to the runway which had been accumulated during extinction. However, this theory did not seem to be tenable in that it would val between two was more than six minutes.

A second hypothesis might be that the introduction of GB 2 would instigate and reduce exploratory drive and thus would increase the response stre. ngth. However, as the animal would not have the exploratory drive at the time when it was placed in SB during post-extinction, the exploration hypothesis seemed inappropriate.

An alternative explanation in terms of drive reduction was that, by the exposure of GB 2 the rats would escape from the frustration which would have accumulated during extinction and conditioned to the apparatus as a whole. The post-extinction according to this hypothesis was essentially escape conditioning. This frustration hypothesis appered to be most tenable but 
in order to strengthen the hypothesis, the following experiments were conducted.

\section{EXPERIMENT II}

A second experiment was run to determine whether the same phemenon as shown in Experiment I would be found with a very long inter-trial time interval. If it did, the disinhibition theory should be definitely ruled out. A group of 11 rats was run following the same procedure as in the previous experiment except that this group was given only one trial per day for 20 days with food and then extinguished for 10 days again one trial a day, and on tenth extinction trial GB 2 was available to the rats. Five post-extinction trials were observed.

\section{RESULTS AND DISCUSSION}

Again the same effect was obtained although it was more clear on the second post-extinction trial and later. It would be unreasonable to believe that disinhibition lasted for 24 hours and thus this interpretation should be excluded.

\section{EXPERIMENT III}

Experiment III was conducted to test the exploration hypothesis. As the same time it was determined whether the effective stimulation should be proprioceptive or it may simply be visual stimulation. A group of 22 rats was run under the same procedure as in Experiment I except that GB 1 was coverd with white paper on and after the critical trial on the second extinction day and D3 was closed throughout the ex- periment and thus the only stimulus change during extinction was the visual one with respect to $G B 1 . G B 2$ was not used in this experiment.

\section{RESULTS AND DISCUSSION}

Figure 2 gives mean log. transformed running times on the second extinction day. The mean on the eighth critical trial was 1.322 and that on the next trial .963. The difference between the two means tested by the mached $t$ test was significant at the .01 level of confidence. The obtained $t$ was 4.02 with $21 d f$.

However, the mean value increased gradually and on the fifth post-extinction trial the obtained mean of 1.466 was greater than that of the critical run, i. e. 1.322 .

The results discouraged the exploration hypothesis since in this experiment the rats had no extra space to explore but the only change in stimulation was visual. It was already mentioned that the lack of exploratory drive in the rats when they were put in SB, was inconsistent with the hypothesis.

One might argue that an increase in intensity of $G B 1$ would facilitate the response strength according to the principle of stimulus intensity dynamism but this did not seem likely on the basis of the fact that the rats could not see GB 1 when they were placed in $\mathrm{SB}$, that is before the response was. elicited.

The results of the three experiments seemed to indicated that the animals had been frustrated in extinction trials. 
since their primary drive of hunger had not been reduced. This frustration drive, on the other hand, would have been conditioned to $S B$ as well as to the alley and the empty goal box. When the rats found a new stimulus situation on the critical trial during extinction, the acquired frustration drive would have been reduced by going to that area which was not conditioned to frustration.

This goal reaction of the escape from frustration, according to the present hypothesis, had been associated with the frustration drive. Thus when the rats were placed in SB on the next trial, the frustration instigated by $S B$, would heve elicited the goal-anticipatory response and would have faciliated the running response.

The present finding was consistent with the Brown and Farber theory of frustration.(1) According to their theory "reactions followed by a reduction in frustration will be reinforced" (1, p. 490), although no empirical evidence was presented by these authors.

\section{SUMMARY AND CONCLUSION}

A group of rats was given 10 training trials per day for six days in a straight runway with food in the goal box. Extinction started six minutes after the last training trial on the sixth training day. The rats were run 15 times without food with an inter-trial interval of six to ten minutes. On the next day the same conditions were used for seven additional trials but on the eighth trial the animals were allowed to enter an extra box through the empty goal box. A significant decrease in the mean transformed running time was observed on the next trial.

In order to explain the results three possible hypotheses were suggested. Both disinhibition and exploration hypotheses were discarded with confidence by the two control experiments. A third and the most appropriate hypothesis in terms of frustration reduction stated that the introduction of a new stimulus situation would reduce the frustration which had been accumolated during extinction and the reduction in frustration would reinforced the following response.

\section{REFERENCES}

1) Brown, J.S., and Farber, 1.E. : Emotions conceptualized as intervening variables-with suggestions toward a theory of frustration. Psychol.Bull., 1951, 48, 465 -495 .

2) Gagne, R. M. : External inhibition and disinhibition in a conditioned operant res ponse. J.exp.Psychol., 1941, 29, 104-116.

3) Horns, H.L., and Heron, W. T. : A study of disinhibition in the white rat. $J$ comp Psychol., 1940, 28, 97-102.

4) Hunter, W. S.: The disinhibition of experimental extinction in the white rat. Science. 1935, 81, 77-78.

5) Reynolds, H. E.: The disinhibition effect of an electric shock upon the maze performance of the white rat. J.com. Psychol., 1936, 28, 187-197.

6) Reynolds, H.E.: Further disinhibition phenomena in the maze behavior of white rats. J.com.Psychol., 1939, of,271282

7) Skinner, B. F.: A failure to obtain 'disinhibition'. J.gen.Psychol., 1936, 14, 127 -135 . 